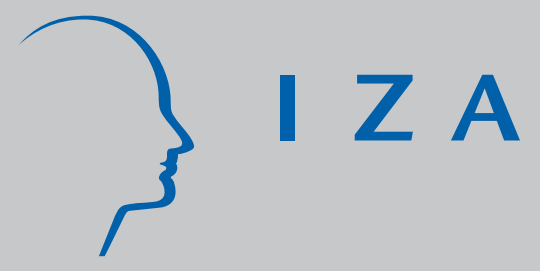

IZA DP No. 63

\title{
Your Everyday, Average Academic
}

Melanie Ward

October 1999 


\title{
Your Everyday, Average Academic
}

\author{
Melanie Ward \\ $I Z A$, Bonn, Germany
}

\section{Discussion Paper No. 63 \\ October 1999}

\author{
IZA \\ P.O. Box 7240 \\ D-53072 Bonn \\ Germany \\ Tel.: +49-228-3894-0 \\ Fax: +49-228-3894-210 \\ Email: iza@iza.org
}

This Discussion Paper is issued within the framework of IZA's research area The Future of Work. Any opinions expressed here are those of the author(s) and not those of the institute. Research disseminated by IZA may include views on policy, but the institute itself takes no institutional policy positions.

The Institute for the Study of Labor (IZA) in Bonn is a local and virtual international research center and a place of communication between science, politics and business. IZA is an independent, nonprofit limited liability company (Gesellschaft mit beschränkter Haftung) supported by the Deutsche Post AG. The center is associated with the University of Bonn and offers a stimulating research environment through its research networks, research support, and visitors and doctoral programs. IZA engages in (i) original and internationally competitive research in all fields of labor economics, (ii) development of policy concepts, and (iii) dissemination of research results and concepts to the interested public. The current research program deals with (1) mobility and flexibility of labor markets, (2) internationalization of labor markets and European integration, (3) the welfare state and labor markets, (4) labor markets in transition, (5) the future of work, (6) project evaluation and (7) general labor economics.

IZA Discussion Papers often represent preliminary work and are circulated to encourage discussion. Citation of such a paper should account for its provisional character. 


\section{ABSTRACT}

\section{Your Everyday, Average Academic}

The data described in this paper come from a unique cross section study collected by the author, using a postal questionnaire, of five Scottish Universities: Aberdeen, Dundee, Glasgow, Heriot-Watt and St. Andrews undertaken in 1995/6. It encompasses detailed information on the personal and working history of 900 academics. The paper aims to provide the reader with a fuller picture of the characteristics of today's average UK academic. Second, it aims to take advantage of this more detailed information to make some comment on the current debate in the UK concerning gender discrimination and underpayment in academia.

JEL Classification: J44

Keywords: Academic profession, underpayment, gender, publication, average characteristics

Melanie Ward

IZA

P.O. Box 7240

D-53072 Bonn

Germany

Tel.: +492283894306

Fax: +492283894210

Email: Ward@iza.org

\footnotetext{
* The background research to this paper was completed during the course of my $\mathrm{PhD}$ at Aberdeen University, Scotland. I gratefully acknowledge the funding for this research provided by the Scottish Economic Society and the helpful comments of my supervisors, Professor Peter J. Sloane and Professor loannis Theodossiou.
} 


\section{Introduction}

This paper focuses on an examination of the experiences of today's academic profession. It presents the characteristics of the average British academic based on information collected from the academic staff of five from Scotland's eight old established universities - Aberdeen, Dundee, Glasgow, Heriot-watt and St. Andrews. These universities are institutions with a strong sense of tradition and respected research reputations. Information is therefore collected from the most research orientated segment of the academic profession, the established universities, as their behaviour may be an important signal to the entire profession. Therefore, although this study is limited to one sector of the British academic workforce, the main conclusions are likely to be relevant to the other sectors of Higher Education in Britain.

This study presents itself at a time when the academic community has heard much about gender discrimination and under pay from sources such as the press and the Bett (1999) report. To date, however, research into the academic labour market in Britain has been scarce. This might be due to, first, the lack of relevant and available information. National statistics, collected by the Universities Statistical Record and later by the Higher Educational Statistics Agency, contain only very limited information. The census of academic salaries collected data on gender, age, date of recruitment, rank, faculty and salary, but ceased in 1993. Information concerning academic staff held by the universities themselves is limited (although more detailed in recent years) and generally very difficult to compile. The largest problem here, however, is access. Second, the UK system of academic salaries is based upon a fixed framework of negotiated salary points for staff up to professorial level where progression along this scale is automatic and largely dependent on years of work. One might therefore deem studies of gender discrimination in the UK academic labour market to be unnecessary.

The aims of this paper are twofold. First, it aims to provide the reader with a more detailed picture of the characteristics of today's average academic. Second, it aims to take advantage of this more detailed information to make some comment on the current debate concerning gender discrimination and underpayment in academia. This paper is written with particular interest in the former and is structured as follows. Discussion is split into six sub sections, each dealing with a group of characteristics. We investigate the age, personal background, education and publication, career history, salary and promotion opportunity and the opinions 
of the average academic. We begin with some background to the current position of women within academia.

\section{Women and History}

Historically, British universities have been made up of predominantly male academics. The recent report by Bett (1999) has awakened suspicion of gender discrimination within the profession. We address the issue of discrimination against female academics during the course of this paper, but gender equality in academia has much wider implications than of those of its staff. Universities are centres for teaching and learning, and particularly with the expansion of students entering higher education in recent years, a large proportion of today's young population will pass through an academic degree. A large number of Britain's politicians, professionals and decision makers are drawn from university graduates.

Several factors suggest that one would expect to find a large number of women in academia. The flexibility of an academic career might encourage women to develop stronger long term work commitments than women in other labour markets through enabling them to combine a career more easily with domestic and family responsibilities. Commitment to the labour market might also be reinforced by the large investments in education required for the job (Mincer and Polachek, 1974). The social element of the job may attract women and as a teaching profession, if only as a result of the limited role history has allowed women in the workforce, we might expect women to work in academia in significant numbers (AUT 1992).

Statistics from the Higher Statistics Agency 1995/1996 on the proportion of women in the U.K academic labour force reveal that this is not the case however. Less than one third of full-time academic staff are women. Female staff are concentrated on the lower rungs of academia, making up 35\% of researchers, but only 8 percent of professors. One out of every three researchers or lecturers, one out of every five senior lecturers and less than one out of every ten professors are women. Mumford (1997) in her study of the gender balance of academic economists in the UK finds a similar pattern of female representation and the crowding of women into the lower ranks. Females are also crowded into certain subject groups. The AUT (1996) reports that amongst researchers, 'women form more than half the 
workforce in librarianship and information science, subjects allied to medicine, social, economic and political studies, languages and education. Women represent less than a quarter of research staff in technology, maths and computing, the physical sciences and engineering.' As lower rung jobs are by their nature more likely to be short term positions, two thirds of female staff are also on fixed term contracts compared with $45 \%$ of men.

We find a similar pattern exists for the academics we describe in 1995-96. The data investigated in this paper was collected though the deployment of a postal questionnaire. Information was collected from 900 academic staff covering a number of personal and career aspects. Women in these institutions are, as in the UK as a whole, predominantly found in the lower rungs of an academic career, with half of the female sample being employed as research assistants and a successively smaller proportion being employed at the lecturer and senior lecturer level. We find that two in three research assistants, 1 in 3 lecturers, 1 in 5 senior lecturers and 1 in 18 professors are female. There are therefore slightly more research assistant posts and fewer professorships held by females in the Scottish Universities considered than in the U.K academic population as a whole. This finding agrees with statistics from Higher Education Statistics Agency (HESA) and the Times higher Educational Supplement. Men are more evenly distributed, with a third of the male sample being employed as lecturers and nearly a quarter of the male sample working in the position of senior lecturer and professor. Arts, medicine and social sciences employ the most women, science and engineering the least. Women in the data set are also more likely to be on short term fixed contracts. Seventy six percent of men but only $39 \%$ of women are in permanent positions. These figures echo those of the AUT (1996) which indicate a substantial shift towards fixed term contracts in academia. In 1990-91 $15.6 \%$ of lecturers in the UK were appointed on fixed term contracts, the corresponding figure in 1994-95 was 49.5\%. Many of the female academics in our sample are therefore likely to be new arrivals who have fallen into this more 'flexible' era of academic contracts.

How does the proportion of women in academia compare with other professions? Twenty nine percent (27\% in Scotland) of U.K academic staff in 1995/6 are female (HESA 1995/96). The Equal Opportunities Commission (1997) find that $30 \%$ of solicitors in the UK are female, $22 \%$ of barristers, $18 \%$ of MPs, $14 \%$ of judges and $14 \%$ of the police. These figures place the gender mix of academics in a relatively good light, but we must keep in mind that 
this is a profession the characteristics of which, we have argued, should particularly attract women.

Menges and Exum (1983) suggest three explanations for the lower proportion of female academics than male. Firstly, the small number of potential and actual candidates, that is, a small applicant pool, secondly, the failure of affirmative action policies and thirdly, a set of distinctive problems faced by women during academic life, in particular during tenure and promotion reviews. To comment on the first of these explanations we might look at the number of students in full time undergraduate study in 1995/96 which reveals that half were female. Women made up $44 \%$ of full-time postgraduates. This is a large improvement on the position of women in the 1970 s when only $22 \%$ of undergraduates and $30 \%$ of postgraduates were female (Williams, Blackstone and Metcalf, 1974). Only 29\% (27\% in Scotland) of our U.K academic staff in 1995/6 are female however. This seems to suggest forces at work on entry to academia that result in a lower incidence of females, whether through gender differences in occupational choice, or some other explanation. Nevertheless, the proportion of women in academia has improved from that described by the AUT in 1992 and offers a substantial improvement from the position twenty years ago (Williams, Blackstone and Metcalf (1974) describe an academic labour force in which women constitute only $10 \%$ of academics $-23 \%$ of researchers, $12 \%$ of lecturers and only $1-2 \%$ of professors). This increase may point to the success of equal opportunities policies and to the changing attitudes towards female academics. Comparing the distribution with the American market, the UK also does relatively well; US figures for 1994 show that women make up only $22 \%$ of lecturers, $10 \%$ of senior lecturers and 4\% of professors (CSWEP, 1995).

The following discussion focuses on those individuals who have already become academics and looks to a combination of factors that might explain the current gender mix within the academia. Possible explanations should be judged against this background of a historical predominance of men in the profession. 


\section{Age, nationality and marital status}

The first interesting and important characteristic of the academic profession to consider is the age of its workers. The older academics in the data set will experience a very different profession today to the one that they entered. Many will have observed the implementation of Sex Discrimination legislation in the 1970s and the changes that this brought and many will have seen the profession become more competitive over the years with the onset of the research assessment exercises, for example, and the increase in short term contracts. As a consequence of this, the older academics in the data set will most likely have required less in the way of formal qualifications, for example, than those entering the labour market now. Female academics in addition to this, will have experienced dramatic changes in society's perception of women at work. In the days of the eldest cohort of academics in the data set, women academics were rare and lower academic standards may have been expected of them. Today, however, with growing opportunities for women in employment, the greater acceptance of equal opportunities and more frequent combining of family and career we find a much higher proportion of women working to the same standards as those expected of men.

Figure 1 presents the proportion of academics in the data set by four age brackets; ages 20 to 29, 30 to 39, 40 to 49 and those over fifty. Three quarters of female academics in the five Scottish universities studied are under the age of forty, compared with only about two fifths of men and the average female in the labour force is nearly eight years younger than the average male of 44. This age gap is larger than that described by the AUT (1992) considering the UK academic labour market as a whole with 1990 data. They find, however, that women are beginning to enter the profession in increasing numbers and argue that this effect simply has not been sustained for long enough to modify the average age figures. Perhaps the timing of the collection of the present data set with its' additional five years has allowed sufficient time for these entrants to influence average figures. The majority of women in the data set are, therefore, young women who will differ greatly in their characteristics from the characteristic of the average male in the data set.

This figure therefore represents a dramatically different gender mix for the four age brackets considered and is suggestive of a profession which may in the future become female dominated. If this were the case, one might ask why such a traditionally male occupation 
would swing to the opposite gender extreme. Declining relative salaries could be one suggested explanation. In the course of this discussion, however, it will be revealed that the vast majority of the young women in our data set are research assistants on short term contracts - a subsection of the academic labour force about which very little is known. The Institute for Employment Research (IER) at Warwick University has recently begun a study into the career paths of these workers and although no evidence is at the moment available, it might be suggested that large numbers of young female academics, either through choice or as a consequence of their short term contracts, will move away from academia within a few years. The large proportion of young females in the lower rungs of academia may not therefore signal such an extreme change in the gender balance of academia as figure 1 suggests.

Turning to the pattern of marital status of our academics. Twice as many women as men are single. Three quarters of all men are married, as opposed to just over half of women. Of the academic staff who have previously been married, females are less likely to have been widowed, more likely to have been divorced and have an equal probability of being separated from their partners. The proportion of married academic staff has not changed too much from the 1970s position described by Williams, Blackstone and Metcalf (1974). The high proportion of single women again reflects the high proportion of young women in the data set. Information on academics' families reveals that eighty percent of the married women in our data set have children, just under a quarter of them having more than two children. This is a significantly different picture to the 1970 s where $30 \%$ of married women were without children and the few mothers had more than two children. Our finding may therefore reflect the more widespread combination of family and career by working women today.

The final personal characteristic to discuss is the citizenship of academics working in Scotland. With the opening up of world markets and moves towards closer European integration it is interesting to consider how international the Scottish academic profession is. Statistics reveal that ninety two percent of female academics in the universities considered are U.K citizens, compared with $88 \%$ of men. These figures are $15 \%$ higher for females and $5 \%$ higher for males than for figures on the U.K as a whole (AUT 1996). This suggests that although the UK labour market for academics is an international one, Scotland might perhaps be regarded as more peripheral than England. 


\section{Education and Productivity}

\subsection{Education}

Educational background can be argued to be particularly important in the study of academia, a profession where educational qualification constitutes the majority of an individual's training and where progression is solely based on academic merit. Statistics reveal that the male academics in the data set are on average more qualified than the female. Three quarters of males hold a $\mathrm{PhD}$ as opposed to $55 \%$ of women. Men are also more likely to have studied for an MSc (38\% of men compared with $30 \%$ of women) and are more likely to hold a qualification other than a degree, such as a professional qualification (48\% of men compared with $42 \%$ of women). This pattern of higher male average qualification holds across subject groups although the gender gap is widest in engineering and social science. Investigating MSc and $\mathrm{PhD}$ ownership by age bracket, we find that the pattern of $\mathrm{PhD}$ attainment is what we might expect, with the gap between male and females widening with age. This is in line with the hypothesis that women in the older cohorts of the academic labour market will hold less in the way of formal qualifications than their male counterparts due to their historically limited role in academia and the lower expectations that they faced. Consideration of MSc holding, however, reveals that women are more likely to hold a MSc at all age brackets, except the age bracket 30-39. Perhaps historically a MSc was considered qualification enough for most women. Younger female academics will most likely be studying for an MSc as a step towards $\mathrm{PhD}$. An additional explanation for this finding is therefore the large proportion of female researchers (45\%) in the data set, some of whom are unlikely to invest in $\mathrm{PhD}$ study in order to proceed into lecturing.

Gender differences in the quality of an academic's education is also important. Figures 2 and 3 analyse where the men and women in the data set gained their first degree and $\mathrm{PhD}$ respectively. Universities were categorised following Johnes and Taylor (1992) and more recently Baimbridge and Simpson (1996) (see appendix for details of this classification). These figures suggest that a higher proportion of male academics than female academics have gained a degree from one of the more prestigious institutions. While for both first degree and $\mathrm{PhD} 15 \%$ of male academics had been to Oxford or Cambridge, this was true for only around $5 \%$ of women. Women are most likely to have gained a degree from the same institution as 
their current job, which is the case for about one quarter of women for their first degree and over one third for $\mathrm{PhD}$. What might explain this apparently closer tie of women to the institution of one or more of their degrees is an interesting question. Arguments over female ambition, lack of confidence and family influences (discussed later in this paper) have been suggested (Williams, Blackstone and Metcalf, 1974). The most likely explanation is that the institution of an individual's degree knows more about that individual's ability and potential productivity. External institutions will know less, perhaps much less, about an individual's productivity and might be less willing to take the risk of employing an unknown female than an unknown male. Female academic staff are also more likely to have gained a first degree from a new university than male academics. For men these proportions are lower at around 20 and $25 \%$ respectively. Most men, in contrast, have received their first degree from an old established university outside Scotland. Around $15 \%$ of the work force have received a first or $\mathrm{PhD}$ degree from an old established university in Scotland.

The five old established universities studied are therefore most likely to recruit individuals who have gained either a first degree or $\mathrm{PhD}$ from a similar type of institution. Over $68 \%$ of women and $75 \%$ of men with a first degree and $80 \%$ of both women and men with a $\mathrm{PhD}$ have been drawn from this university pool. There is evidence of a shift away from the Oxbridge domination of academic staff described by Williams, Blackstone and Metcalf (1974) towards graduates of the old established universities. The younger women in our data set are particularly less likely to have studied at the former institutions.

\subsection{Productivity}

Papers studying US academia argue that females have a lower productivity than comparable males and that these productivity differences may explain observations of lower female pay. One might expect women in the academic profession to be carefully selected by universities that is, only the most productive will be employed (Williams, Blackstone and Metcalf 1974). Evidence suggests that the males in the data set are on the whole more productive than the females, however. They have published more books, chapters and refereed articles and produced more conference papers on average than females. The average number of books published is 1.44 for males, but .39 for females. The corresponding averages for chapters in 
books written is 3.93 and 1.12, for refereed articles, 32.38 and 7.79, and for conference papers 14.92 and 7.10. Comparing the proportion of staff that have never published an book (article) reveals that $77.1 \%(24 \%)$ of females in the data set have not published an book (article) compared with $53.9 \%$ (13\%) of males. Four percent of women have published more than three books compared with $13.0 \%$ of men. These figures are remarkably similar to the situation described by Williams, Blackstone and Metcalf (1974) 20 years ago. Even when accounting for differences in age and experience between the two sexes to allow for the longer time that male academics in the data set have had to publish, men continue to outpublish women. They have also acquired more fellowships, offices and grants than females per year of experience.

Taking subject, in addition to age and years of experience, into account the picture becomes less clear cut. Women generally do better in the youngest cohort - age 20 to 29 - where women out-publish men in the areas of social science, medicine and the arts. Men continue to out-publish women in science and engineering. In the age cohort 30-39 female academics outpublish men in the number of books they produce in the arts and social sciences, but males are more productive in article production and in all publications in the other subject areas. Consideration of publication by rank supports the evidence that female researchers and senior lecturers in the arts, social sciences and medicine are marginally more successful. The evidence for the other cohorts, however, is again in line with the lower levels of female publication.

Williams, Blackstone and Metcalf's (1974) find that the married women with children in their data set are the female academics who publish the most and are the only group of female academics which publish equivalent quantities to comparable males. We find that the youngest single women perform better than married women, but married women do publish comparatively more in the older cohorts, although they do not manage to catch up with their male counterparts. The evidence concerning women with children is mixed. Older men with children, however, do better than their younger contemporaries without children.

What explanations can be given to begin to explain why women under publish? One suggestion is that women are employed predominantly for their teaching skill and have higher teaching and administrative loads and limited time for publication. Evidence from this data 
set, however, reveals that the males and females have on average comparable teaching skill an average assessment of three on a scale of 1 to 5 and that more women than men are primarily research orientated in their job. More men than women hold a primarily teaching based position and nearly twice as many women as men indicated that their job is primarily research based. This corresponds with the high number of female research assistants in the data set and the majority of male academics working as lecturers. Have women simply become more research orientated, without becoming more productive as suggested by Williams, Blackstone and Metcalf (1974)? Alternatively it has been suggested that women may simply be less ambitious, and may under aspire academically. It is hard to believe that after such intensive investment in education in the build up to entering academia, that women would then sit back and lose their standing, however. Differential tastes for publication by gender and lower female mobility as explanations for lower female publication are discussed in following sections of this paper.

Considering hours of work, summary statistics reveal that the average male academic, working 52 hours per week, works five hours longer than the average female and, in taking 23 days holiday per year, takes 5 days holiday less. Women work consistently fewer hours over all four age brackets, with the largest gender difference for the age 30-39 cohort. This may well correspond with increased family and household responsibility for the women within this age band. Figure 4 shows the average hours worked by rank for men and women. Female academics work consistently shorter hours than their male counterparts at every rank, except senior lecturer where women work longer hours than men. The longer hours worked by these women may reflect their attempts to gain promotion to professor. Hours are generally found to increase with seniority. Results therefore suggest that we do observe some gender differences in preferences for working hours. Court (1994) finds the opposite gender effect that women work longer hours on average than men. Evidence from the US however has also found that men generally work longer hours than women (see for example, Johnson and Stafford, 1974). 


\section{Career History}

Turning to the labour market experience of individuals in the data set, we find that the average male has worked in his present job for longer than the average female academic ( 8 years for the average man and 3 years for the average woman) and has had a longer tenure with his present employer (12 years as opposed to 5) and more experience in the academic labour market (18 years as opposed to 10). A higher proportion of women (10\%) than men (7\%) have had less than 3 years experience in the academic profession. In contrast, more men (64\%) than women (32\%) have worked there for 15 years or more. Male and female academics have very similar levels of labour market experience in all age cohorts. This evidence points to men generally having spent longer in the profession than women and ties in with the historical predominance of male positions. The difference in average experience for men and women is greater than that described by the AUT (1992), is symptomatic of the higher proportion of young women in this data set, and suggestive of the more frequent entry of women into academia today.

In view of the fears of the AUT (1992) that gender salary differentials in academia are due to women being penalised for taking career breaks, we also investigate the information available in the data set on time away from work. We find that five times as many women as men have taken a break from work. Nearly $50 \%$ of female respondents have at some point in their career had time away from their career and seventy percent of these breaks were due to pregnancy or childcare. One third of women respondents stated that they had left work to have a child and $11 \%$ had left work to look after children. Consideration of career breaks resulting from unemployment reveal that twice as many women have been unemployed in the data set as men, $11.6 \%$ of women compared with $5.6 \%$ of men have taken breaks from work due to unemployment, and those women who have been unemployed have spent an average of three months longer away from work, 11.30 months as opposed to 8.59 months. This finding could be symptomatic of the higher proportion of women than men on short term contracts. Of those who have been unemployed, the number of spells of unemployment have been about the same for men and women, however (an average of 1.5).

The average time away from work for a female academic is only slightly more than one year, although breaks for childcare were found to be considerably longer, lasting five and a half 
years on average. Thus, although women are more likely than men to take a break from work, the majority of breaks are short term. The problem of, even short, career interruptions may be particularly severe for female academics, however, given that advancement is based solely on specialised knowledge which may depreciate rapidly (McDowell, 1982).

In a highly competitive academic labour market academic staff will benefit from gaining variety in their experience. Academics will often seek visiting positions in quality institutions and move post periodically to attract competitive salaries and research opportunities. Mobility is therefore often advantageous. Summary statistics indicate that female academics in the data set have less experience across institutions than their male counterparts (Males have on average worked at more institutions than females - 2.4 for males compared to 1.9 for females), but surprisingly, women have held a slightly higher number of posts (3.6 for women as opposed to 3.4 for men) which may reflect the greater turnover of jobs for those on short fixed term contracts. A higher proportion of women have worked outside academia (43\%) than men (36\%) albeit for a shorter average length of time (4.3 years for women and 5.4 years for men). The majority of academics move jobs either within their current institution or to other old established British universities. It appears, therefore, that staff move in the main between universities of similar status. A substantial proportion of male staff have also come from a foreign academic institution which, due to the small proportion of non U.K citizens in the data set, most likely reflects British nationals returning from jobs abroad.

The greater productivity of male academics, therefore, may well be due to their greater commitment to an academic career and the contacts they build through mobility between institutions. If men are contributing more effort and are therefore able to build up a larger network of research contacts than women, this would explain their higher average publication rates. Kolpin and Singell (1996) have also suggested that co-authorship is frequently between authors of the same gender. The majority of men in the academic labour market therefore ensures that men will have much greater opportunity to publish. 


\section{Salary and Promotion}

\subsection{Gender Salary Divide}

Discussion of gender discrimination within and underpayment of the academic community require some detailed investigation into the salary position and promotion chances of the average academic. Starting with salary, our information reveals an average salary of $£ 22,054.73$ for women and $£ 28,345.67$ for men. Women in the five Scottish universities studied are therefore paid an average of $78 \%$ of male academic salaries. This is lower than the 83.9\% quoted by the AUT for 1990 and 85\% quoted by McNabb and Wass (1997) using 1992 data and reflects the inclusion of research assistants in the data set. If researchers are excluded from the data, the average female salary as a proportion of the average male's increases to $85 \%$.

The salary position of our female academics is better than that of women in the Scottish working population as a whole who earn between $72 \%$ and $80 \%$ of male pay (Equal Opportunities Commission, 1997). But a natural question is should there be any gap between male and female pay at all? A very important factor in the answer to this question is the far higher age and experience of the average male academic. One must be careful in interpreting statistics on average salary that do not take this into consideration. Part of the divide will reflect the fact that men have simply been around longer and will have had time to gain more experience, proceed further up salary grades and be promoted.

We therefore also consider the age, rank and subject of individuals in the data set in order to provide a more detailed picture of the true gender salary gap. Figure 5 shows the relationship between the average salary and age of respondents. Men and women are found to earn about the same between ages 20 and 36-40. Women then experience a period of lower average pay than their male counterparts until the age of about 63 when female average salary rises above that of males. This pattern is similar to the relationship presented by the AUT (1992). What could explain the gender gap in salary between the ages of 36-40 to 63? One suggestion is that it represents the effect of women leaving the labour market to bring up their families. The role of family responsibility is discussed further in the next section. Alternatively, the gap could reflect men being appointed on higher salary points on entry to an institution, hurdling 
points or receiving discretionary awards or promotion more readily than women in the 36-40 to 63 age range. Notice the slightly higher starting salary of young men. We discuss promotion later in this section.

Evidence from our data concerning discretionary awards reveals that about $80 \%$ of female academics in the data set and $60 \%$ of males were found never to have received a discretionary award. Women have received fewer discretionary awards at all age brackets, except age 20 to 29 where the average is slightly higher for women than men. The female deficit is especially marked for the age 40-49 age group. Comparing these rates with the number of discretionary awards applied for we find that women have on average also applied for fewer awards than men, although the lower application rate by women is not sufficient to explain fully the higher number of awards for male academics. Our first suggestion regarding the explanation of the gender salary gap is therefore that part of the gender difference in salary between the ages of 36-40 and 63 may reflect males receiving discretionary awards more readily than women, although women should be encouraged to more readily apply for the awards.

Turning to figure 6 , the average salary of men and women by rank suggests that there is no difference between male and female salaries within rank. The results indicate that those women who manage to become senior lecturers and professors do not suffer a disadvantage in pay terms. Unlike the AUT, we find that women are actually paid more on average at the rank of professor, although due to the small sample sizes one must be careful in making too much out of this. These results do not rule out differences in male and female reward resulting from the distribution of males and females between grades however. Women are concentrated on the lower ranks of the academic ladder and may find the hurdle of promotion difficult to cross. Policies which aim to alter the female distribution across rank will therefore need to consider equal opportunities policy at promotion decisions. The gender salary differential might therefore be due to the more rapid promotion of men from the age 36 onwards.

Investigating male and female average pay by faculty, female staff are found to receive a lower average pay than male staff in all subject groups. This result agrees with findings by the AUT (1992), the difference being largest in medicine. We find that smaller percentages of women than men are paid across ranks on the clinical scale - a scale for clinical staff characterised by higher levels of pay at every salary point. This may explain part of this 
finding. Much of this differential however is likely due to the differences in rank and experience between men and women.

Evidence presented in this section therefore suggests the importance of differential receipt of discretionary awards and barriers to promotion as important in the explanation of the gender salary gap (for a more detailed analysis see Ward 1999).

\subsection{Household Responsibility}

During the course of this paper household responsibility and its conflict with female work has been suggested as an important influence on academic's behaviour. A women's role as mother and homemaker is often put forward as an explanatory factor in any discussion of women's role in the labour market. Do household responsibility and the presence of children directly affect academics' decisions? and to what extent?

Figure 7 presents the proportion of men and women who revealed that they have been required to make a particular employment related decision or who have been prevented from taking a particular employment based course of action because of the influence of household responsibility. From the eight different decision scenarios which were questioned (see question 3.12 in Appendix) only two affected men more than women, and these were both related to taking a second job. Nearly a quarter of the female academics in our data set, but only one twentieth of the male have been prevented from accepting a full-time job due to household responsibility. An equal proportion of women have also been prevented from looking for a job compared with one tenth of men. Men and women have been equally prevented from changing jobs or taking a second job due to household responsibility, but women were also more likely to have been prevented from accepting a promotion due to household obligations. Finally, three times as many women as men have been required to change their job and $10 \%$ of women have been required to leave employment for more than one year. This is in comparison with a negligible number of men.

These results suggest that women are more directly influenced in their primary employment decisions by the presence of household responsibility than men. This is what we might expect 
when considering the biological role of women in childcare and the traditional role of women in the family. Although male and female academics claim to spend nearly the same amount of time on average doing housework - 10 hours each per week, women spend more than twice as many hours than men looking after the family and it appears the flexibility of an academic career is not enough to influence this family/work trade-off in the direction of work. This finding is unlikely to be unique for academics however and points to the problems faced by many working women.

Turning to the main reason behind individuals' decisions to reject the last job offer they rejected we reveal further evidence of family influence on work related decisions. Family responsibility was the most frequently quoted reason by women for rejecting a job, affecting one third of respondents. Men were most concerned about poor research opportunities, mentioned by nearly $20 \%$ of male replies. In comparison, fifteen percent of men said that family responsibility was the reason for rejecting their last rejected job offer. Pay and permanency of position were equally important considerations for men and women in the data set. In summary it appears that even in the case of a very highly educated female workforce with a strong professional commitment relative to the general population, household responsibility has a significant impact on job related decisions.

\subsection{Promotion}

Turning to the consideration of promotion, we find that three quarters of female academics and one half of the male academics in the data set have never been promoted. When asked if they would like to be, nearly $90 \%$ of women compared with $80 \%$ of men stated they would. This is a surprising result. The question was originally asked as it was anticipated that a higher proportion of women might be happy in their present post and not want to be promoted - one explanation for the crowding of women into the lower academic ranks. This result however indicates that either women are more ambitious than men, or that they are under promoted. Figure 8 shows the average number of promotions received by men and women by age bracket. Women have fewer average promotions than men in every age cohort. The fact that a larger proportion of women $(10 \%)$ than men $(7 \%)$ have had less than three years experience in the academic labour market may explain the differential at the lowest age 
brackets. It does not however explain the widening of the promotion gap with age. The analysis of male and female average promotion by faculty reveals a similar pattern of lower average female promotions in all faculties, the largest differential being found in the science and social science faculties.

If promotion is dependent solely on academic merit, the earlier finding of lower average productivity of women in the data set may explain gender differences in promotion rates. The finding that women have moved university less frequently than men on average might also help to explain their lower promotion. Alternatively, the differential promotion rates between men and women may be unjustified.

\subsection{Underpayment}

Turning to overall levels of pay we asked academics what they thought about their salary in relation to how much they felt they deserved to be paid and asked them to state a figure for the 'deserved' salary they had in mind (see questions 4.9 and 4.10 in appendix). Figure 9 shows to what extent male and female academics believe that they are underpaid, overpaid, or paid about what they deserved. Over half of female academics and $65 \%$ of male academics reported that they were underpaid. Nearly all of those remaining stated that they were paid about what they deserved, only $2 \%$ of women and $2.5 \%$ of men said that they were paid more than they deserved.

Given that it is generally accepted that academic salaries have fallen behind those of other professional groups the fact that over half of the academic population studied believed that they were being paid less than they deserved is hardly surprising. Salary is often perceived by workers as an indication of their value or success at work. Does this mean that over half of academics also feel undervalued? These results would certainly seem to indicate a dissatisfied work force. This finding prompts the question "Why do academics continue to work inside academia if they feel themselves underpaid?". The most obvious answer is that they are not solely concerned with pecuniary reward, but balance pecuniary reward against the positive non-pecuniary aspects of their job where the latter may counterbalance any disadvantages of the former. Evidence suggests that academics may place a lower emphasis on pecuniary relative to non-pecuniary aspects of work than in other sectors of the workforce (see Ward 
and Sloane 1999). Strikes over pay during 1996 and 1999 however are suggestive of a profession on the edge of their reservation salary and the profession may be at risk of loosing its best talent to competing occupations and/or positions abroad.

Academic were asked how much they would have to be paid to move jobs. Both men and women indicated that they would require financial incentives to move job. Excluding a couple of outliers who indicated 1 million pounds, the average moving salary was found to be $£ 23,622.93$ for women and $£ 33,898.93$ for men. The average female would, therefore, only request $£ 1,500$ to move jobs, whereas the average male would need almost $£ 6,000$. These figures correspond with the figures collected for academic ideas of their deserved salary. Both male and female academics would therefore be prepared to move were they offered the salary that they believe they deserve. Increased pay might be the only successful future means to maintaining recruitment levels.

\section{Academic Opinion}

The final section of this paper considers academics' own opinion of the job that they do, the advantages and disadvantages of academic life and what factors are important to them within it. Figure 10 presents the results of asking academics what advantages an academic job has to offer them over any feasible alternative job with their current qualifications and experience. Advantages are ranked in order of importance. Nearly $90 \%$ of academics cited interesting work as an advantage of academia and three quarters felt that flexible working hours were an advantage. The first of these findings is not surprising when one considers that most academics decide the direction along which their work will proceed based on their research interests. The second result suggests that academics do regard the academic working environment as flexible and regard this flexibility as an advantage.

The third largest advantage of academia quoted - the opportunity to teach - provides the first interesting gender difference in academic opinion. Fifty five percent of men, but only $40 \%$ of women cite the opportunity to teach as an advantage of academia. Women may not regard teaching as an advantage of academic life as at least a proportion of the alternative jobs open to them will involve teaching - perhaps a larger proportion than the male equivalent. 
Williams, Blackstone and Metcalf (1974) also find evidence to suggest that men are more orientated towards teaching than women. They suggest that women might be trying to get away from their traditional roles.

Half of the academic population view the opportunity to travel and a relaxing working environment as an advantage of academia, most probably experience travel through conference visits and periods of research at foreign establishments. Nearly half of academic men and a slightly smaller proportion also cite the opportunity to hold responsibility as an advantage of academia. The second gender difference in the reported advantages of academia is in job security. While $37 \%$ of males cite job security as an advantage, only $15 \%$ of women agree with this opinion. This result may well reflect the high proportion of women on fixed term contracts. Comparatively small proportions of academics view geographical mobility an advantage. This is an interesting result given that the academic profession could be argued to be one profession that allows an individual opportunities to work more or less anywhere in the world. Finally, three percent of the sample consider there to be no advantages of academia at all.

Figure 11 considers the potential disadvantages of an academic job outlined by the academics in the data set. The most significant disadvantage cited by both men and women is salary. Seventy percent of males and $58 \%$ of females indicated this to be the case. This ties in with earlier comments on underpayment. A smaller opportunity for promotion than in other occupations is the second most serious disadvantage for female academics with $56 \%$ of the female labour force commenting on this. This element is not such a serious problem for men, who we have seen are more likely to have been promoted. Forty percent of both men and women however agree that a limited promotion path is a disadvantage.

The academic profession is criticised by some as being divorced from the real world. When asked whether or not they agreed with this opinion, only $20 \%$ of men and $11 \%$ of women responded 'yes'. Only $12 \%$ of men and $4 \%$ of women agreed that less supervision was a disadvantage of academia. Finally, just over ten percent of the labour force could not think of any disadvantages of academic life. Thus, at least $10 \%$ of the academic labour market are entirely happy with it. 
Discussion now turns to the factors important to academics in their choice of job and in their current position. Considering the former first (see figure 12), women consistently ranked all options apart from teaching as more important to them than their male counterparts. The pattern of importance overall was the same for men and women. Most important was the working environment, a universities' reputation and the research specialisation of a department. These priorities are consistent with a highly educated workforce with a strong professional motivation. Slightly less important was location, salary and teaching, considerations about which academic are more flexible. Finally least important were hours of work which allow academics most flexibility.

Of the factors important in current job (see figure 13) women again ranked all factors higher than males, although the pattern of response was the same for both men and women. Most important was the opportunity to use one's own initiative. Good relationships with colleagues, working environment, mentally demanding work, the opportunity to hold responsibility and good relationship with seniors all grouped around an average of just under

6. There is a significant gender difference in the importance of a good relationship with seniors which is more important for women than men. Perhaps this reflects a female perception that they must get on well with their seniors in order to be successful in a male dominated profession. Flexible working hours and salary fall into the next band of important factors. This corresponds with the previous argument that academics might be expected to be less concerned about the sole pursuit of high pecuniary reward. Finally the least important influence cited is a stable annual salary, harmonious with the current trend towards ever shorter contracts in the academic labour market.

\section{Conclusion}

The foregoing discussion presents statistics for the average academic based on information from five old established universities. We describe a profession where women are found on the lower rungs of academia, are crowded into certain subject groups and are likely to be on short term contracts. They exhibit a lower level of published output on average than men and have, as a consequence or not, received fewer promotions. They also receive lower salaries than academic males on average. They are less mobile between institutions than men and are 
five times more likely to take a break in their career. They are influenced by family responsibility in decisions relating to employment.

There is evidence of a greater number of women entering the profession in recent years. These young women outpublish their male counterparts in some subject areas and have greater tenure and a longer work experience. They are better qualified and are more research orientated in their principal work activities.

These findings are suggestive of a changing academic labour force, although with the increase in short term contract positions, it is uncertain how long these young women will stay within academia. The progress of women within the profession is slow with 25 years having passed since the implementation of equal opportunities legislation.

The detailed information provided by our data allows us to make some comment on the recent suggestions of gender discrimination and underpayment within the profession. From information regarding salary we find evidence of a gender salary gap in the universities studied, which may arise through first, the lower female receipt of discretionary awards (although we suggest that females should also be encouraged to apply more), second, females being placed on lower starting grades and third, females being less likely to be promoted from age 36 on. Evidence from reports of individual's perceived deserved salary suggest a dissatisfied workforce, the vast majority of which consider themselves underpaid. The average individual would only require their deserved salary to move jobs, suggestive of a work force on the edge of its reservation salary and the profession may be at risk of loosing its best talent to competing occupations and/or positions abroad.

Statistical evidence suggest that policies to encourage the progression from researcher to lecturer, possibly through the reduction of short term contract use, policies to ensure equal treatment of men and women at the level of the tenure/promotion decision (AUT 1992) and to actively encourage women with families to combine family and career may all address many of the sources of current gender differences. 


\section{References}

Association of University Teachers (1992), Sex Discrimination in Universities: Report of an Academic Pay Audit carried out by the AUT Research Department, AUT, London.

Association of University Teachers (1996), Negotiator Factfile, No. 12, October issue.

Baimbridge, M. and Simpson, C. (1996), Rewards to Academia: the remuneration of vice chancellors and Principals, Applied Economics, Vol. 28, pp.631-639.

Bett, M. (1999), Independent Review of Higher Education Pay and Conditions, report of a Committee chaired by Sir Michael Bett.

Committee on the Status of Women in Economics Profession, (1995), Annual Reports, Winter Issue, CSWEP Newsletter.

Equal Opportunities Commission (1997) Facts, Equal Opportunities Comission, Mancester.

Higher Education Statistics Agency (1995/6) Resources of higher education institutions.

Higher Education Statistics Agency (1995/6) Students in higher education institutions.

Johnes, J. and Taylor, J. (1992), The 1989 research selectivity exercise: a statistical analysis of differences in research rating between universities at the cost centre level, Higher Education Quarterly, Vol. 46, pp.67-87.

Johnson, E and Stafford, F. P. (1974), The Earnings and Promotion of Women Faculty, The American Economic Review, Vol. 64, No. 6, pp.888-903.

Kolpin, V. W. and Singell, L. D. (1996), The Gender Composition and Scholarly Performance of Economics Departments: A Test for Employment Discrimination, Industrial and Labor Relations Review, Vol. 49, No. 3, pp.408-423. 
McDowell, J. (1982), Obsolescence of Knowledge and Career Publication Profiles: Some Evidence of Differences among Fields in Costs of Interrupted Careers, The American Economic Review, Vol. 72, No. 4, pp.752-768.

McNabb, R. and Wass V. (1997), Male-Female Salary Differentials in British Universities, Oxford Economic Papers, Vol. 49, pp.328-342.

Menges, R. J. and Exum, W. H. (1983), Barriers to the Progress of Women and Minority Faculty, Journal of Higher Education, Vol. 54, No. 2, pp.123-144.

Mincer, J. and Polachek, S. (1974), Family investment in Human Capital: Earnings of Women, Journal of Political Economy, Vol.82, No. 2, pp.S76-S108.

Mumford, K. (1997), The gender balance of academic economists in the UK, On Behalf of the Royal Economic Society Women's Committee, Department of Economic and Related Studies, University of York.

Ward, M. E. and Sloane, P. J. (1999), Job Satisfaction within the Scottish Academic Profession, IZA Discussion Paper No. 38.

Ward, M. E. (1999), Salary and the Gender Salary Gap in the Academic Profession, IZA Discussion Paper No. 64.

Williams, G., Blackstone, T. and Metcalf, D. (1974), The Academic Labour Market: Economic and Social Aspects of a Profession, Elsevier Scientific Publishing Company. 


\section{Appendix}

3.12 Have household responsibilities ever: (Please CROSS all that apply)

prevented you from: looking for a job?

accepting a full time job?.

accepting a promotion?

changing jobs?.

taking a second job?

required you to: change your job?

leave paid employment for more than one year

None of the above

take a second job?.

5.9 All things considered, which of the following statements do you feel

best describes your present salary?

Much less than I deserve.

Somewhat less than I deserve.

About what I deserve.

Somewhat more than I deserve

Much more than I deserve.

5.10 In your view, what salary do you deserve to get per annum?

$£ .$.

Categorisation of university of study variables: Based on Johnes and Taylor (1992). Dummy

variables are created relating to whether an individual has studied at:

either Cambridge or Oxford,

the same university as their current job (current University),

a Scottish old established university,

another UK old established university,

a Scottish green field site university,

an other UK green field site university,

a Scottish ex college of advanced technology or previous polytechnic and colleges funding council sector institution (noted as a new university),

an other UK ex college of advanced technology or previous polytechnic and colleges funding council sector institution (noted as a new university),

a foreign higher education establishment,

Other. 
Figure 1 Percentage of male and female academics by age

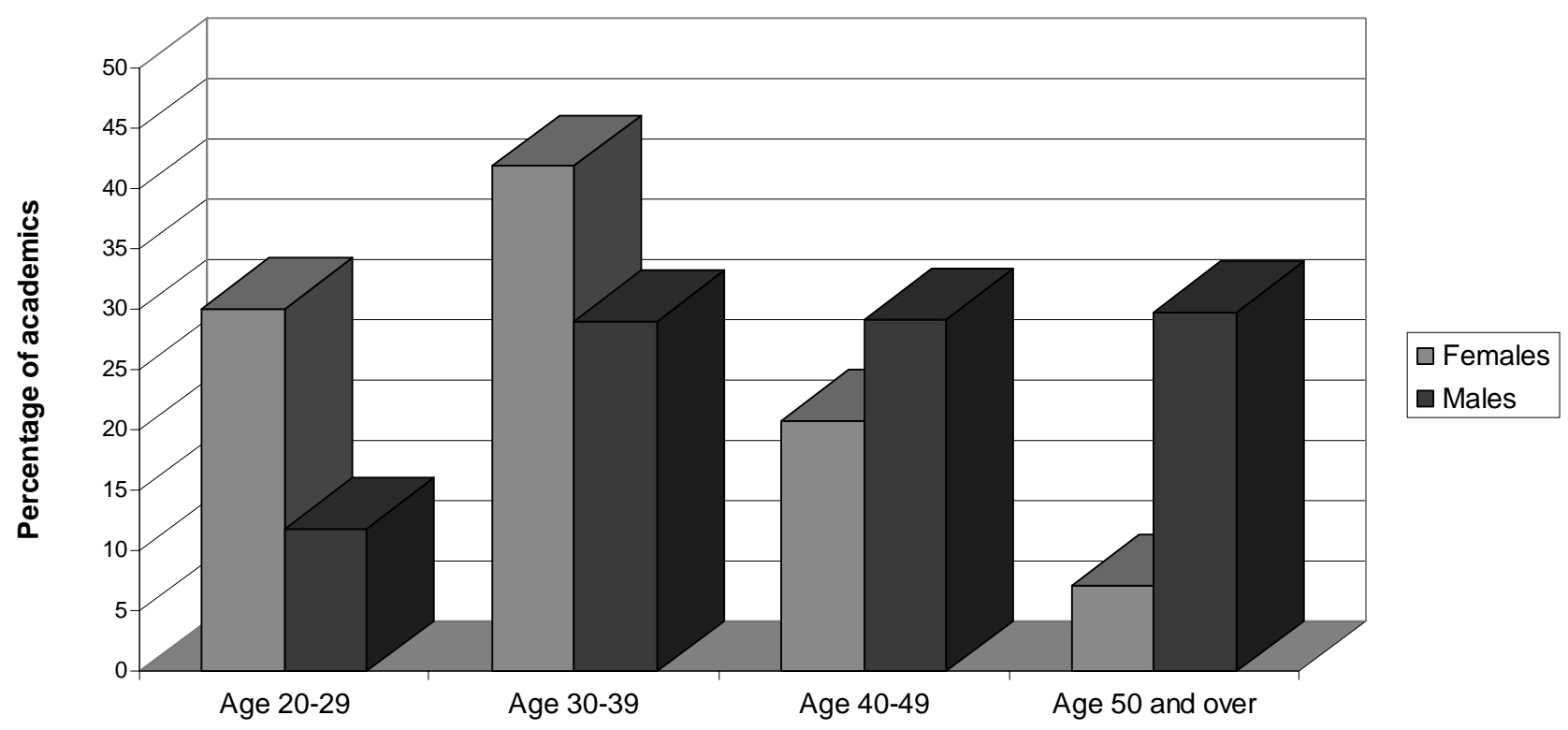

Figure 2 Establishment of first degree

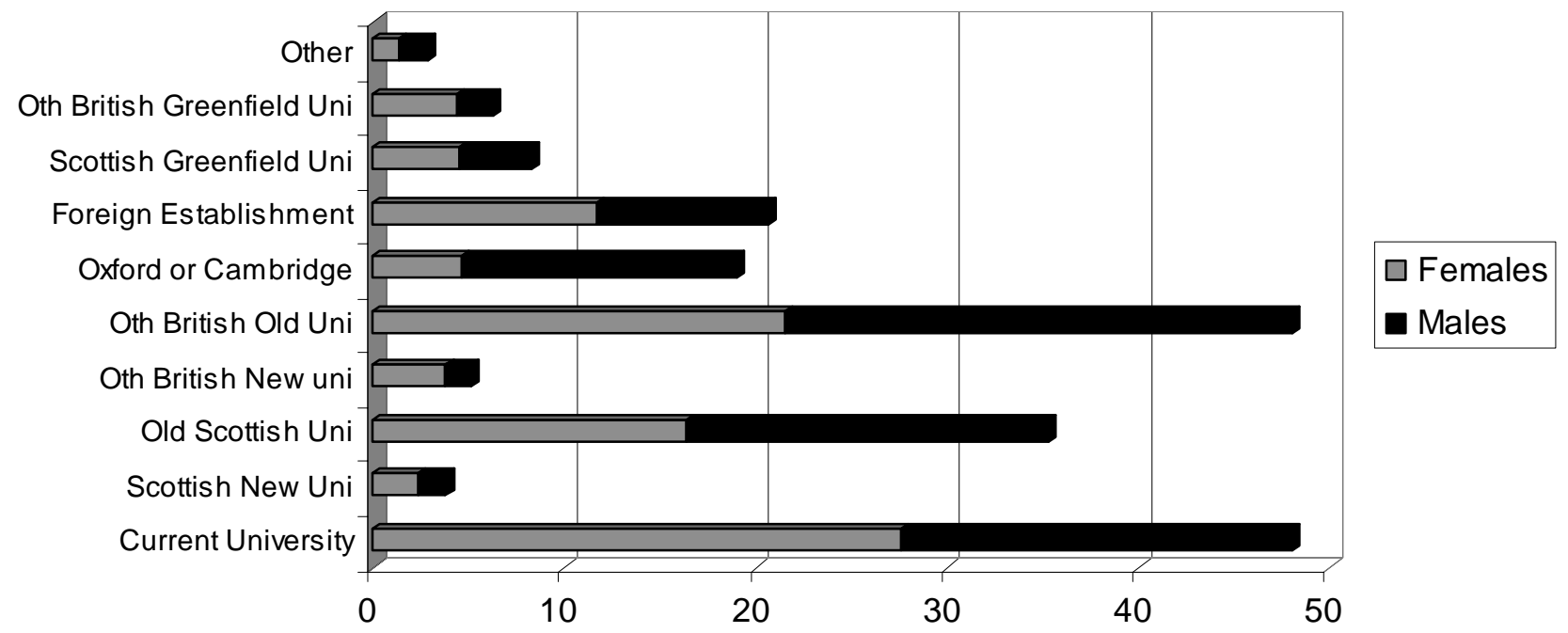


Figure 3 Establishment of $\mathrm{PhD}$

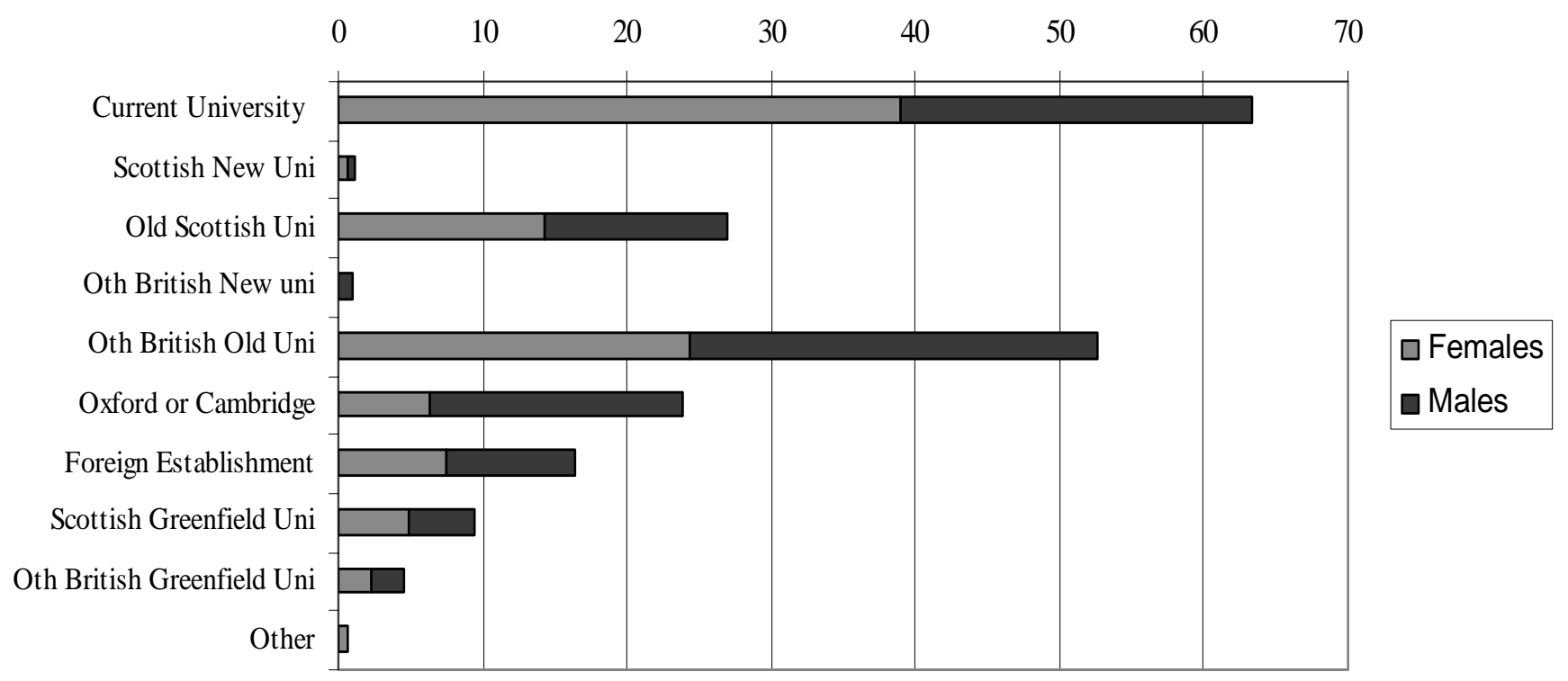

Figure 4 Hours of work by rank

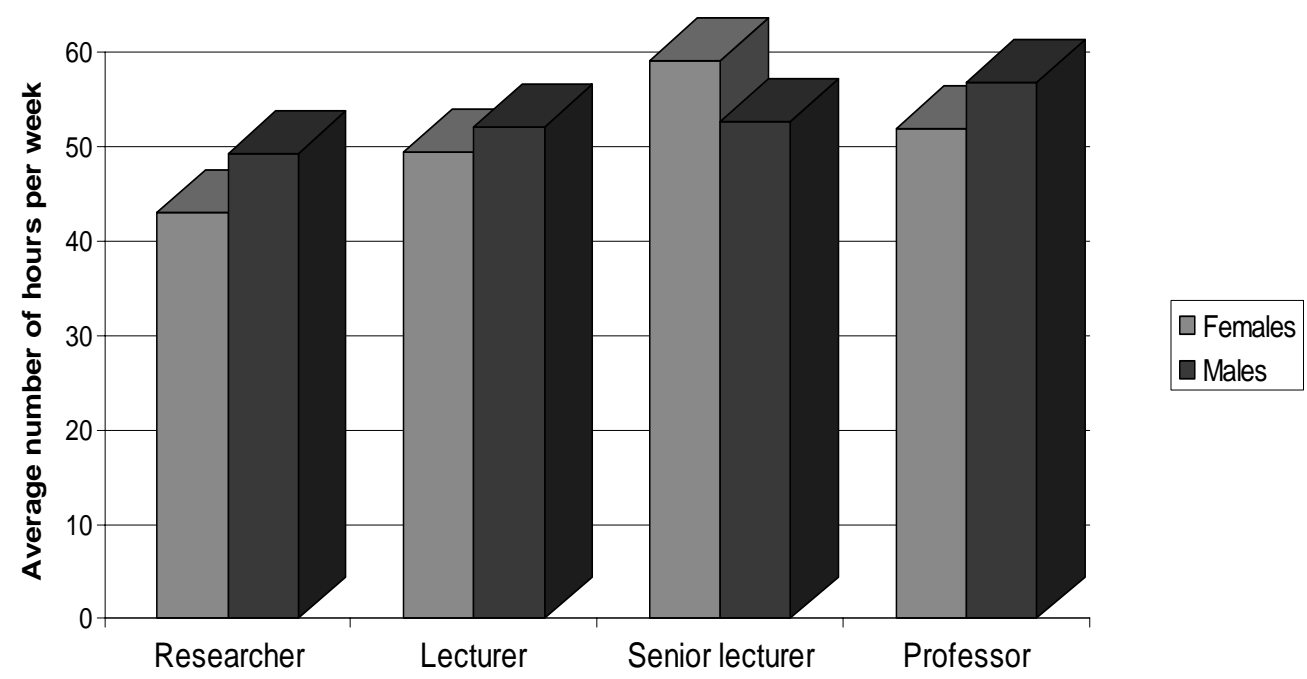


Figure 5 The salary-age profile for males and females

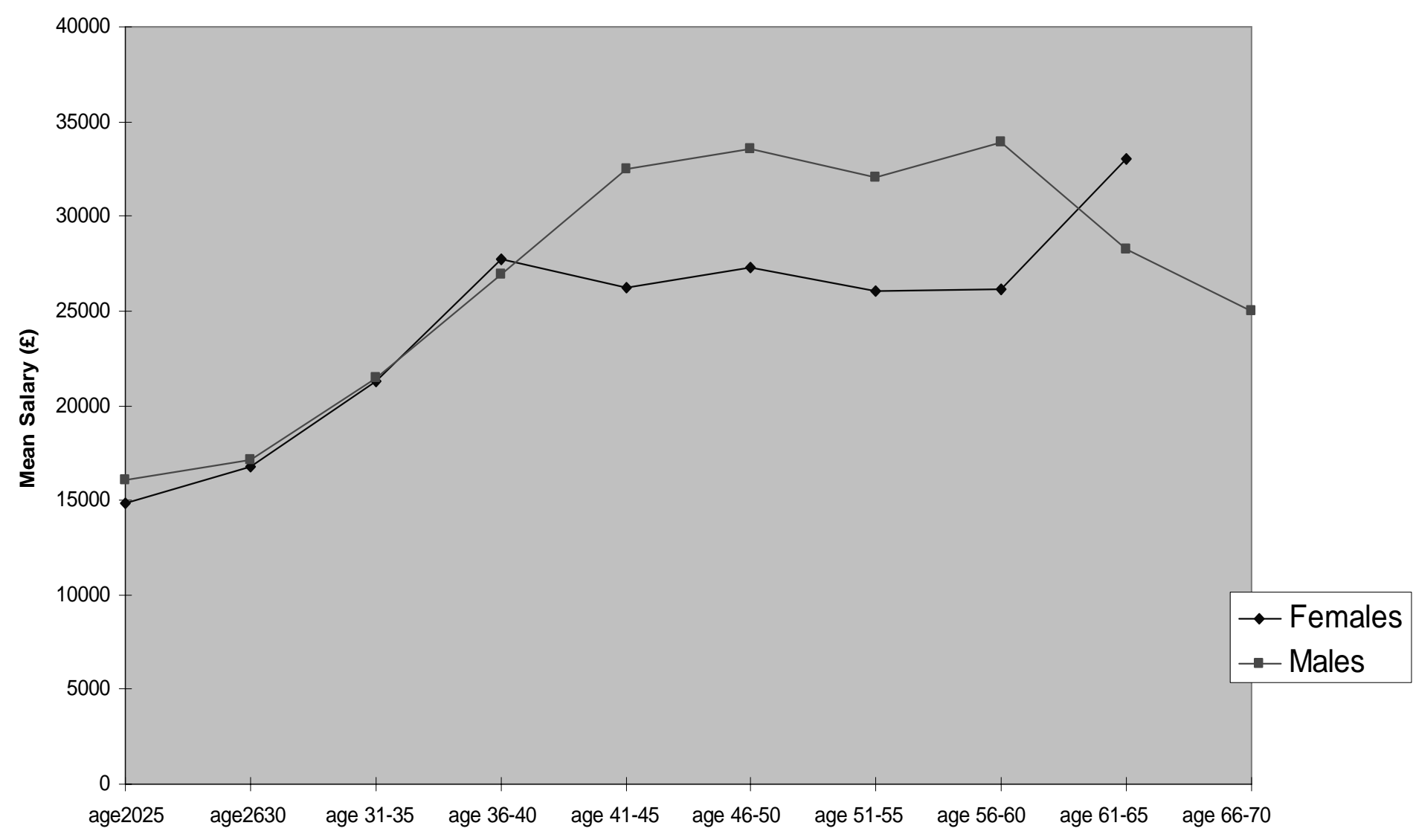


Figure 6 Average Salary of men and women by rank

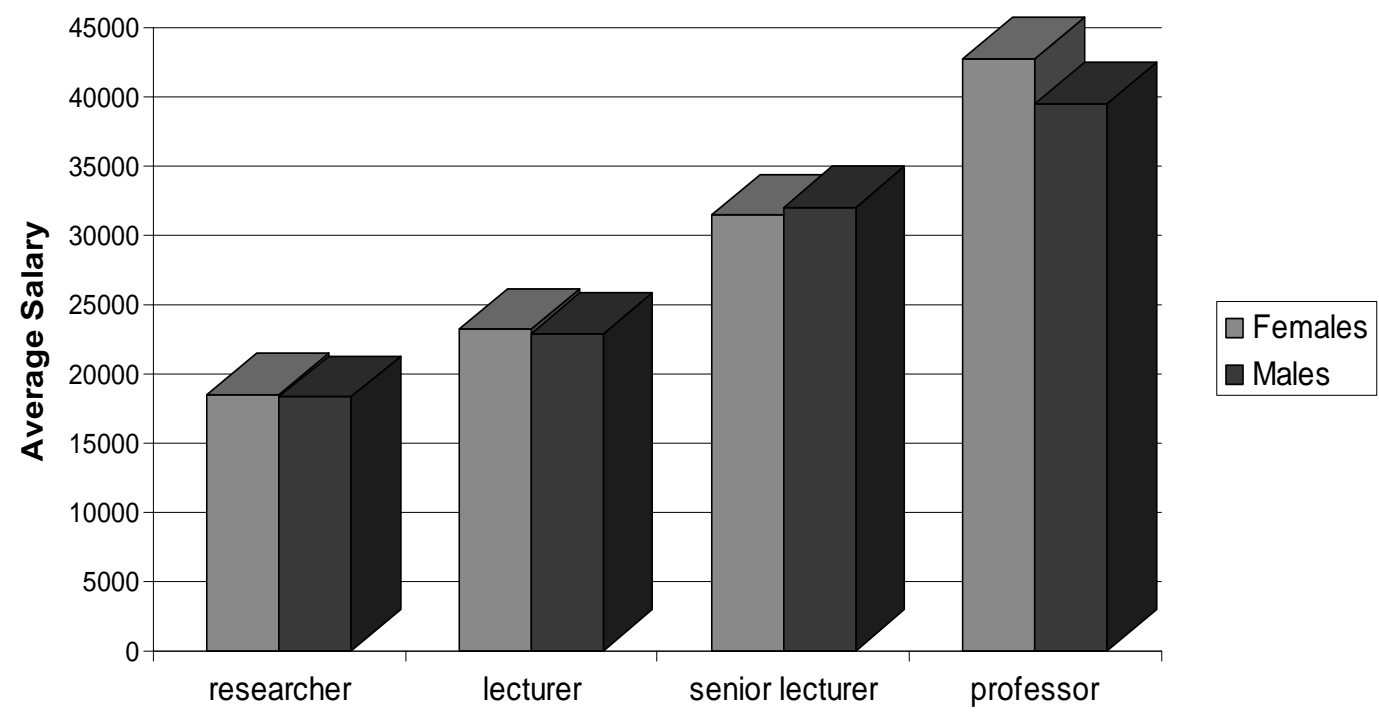

Figure 7 The influence of household responsibility on job decisions

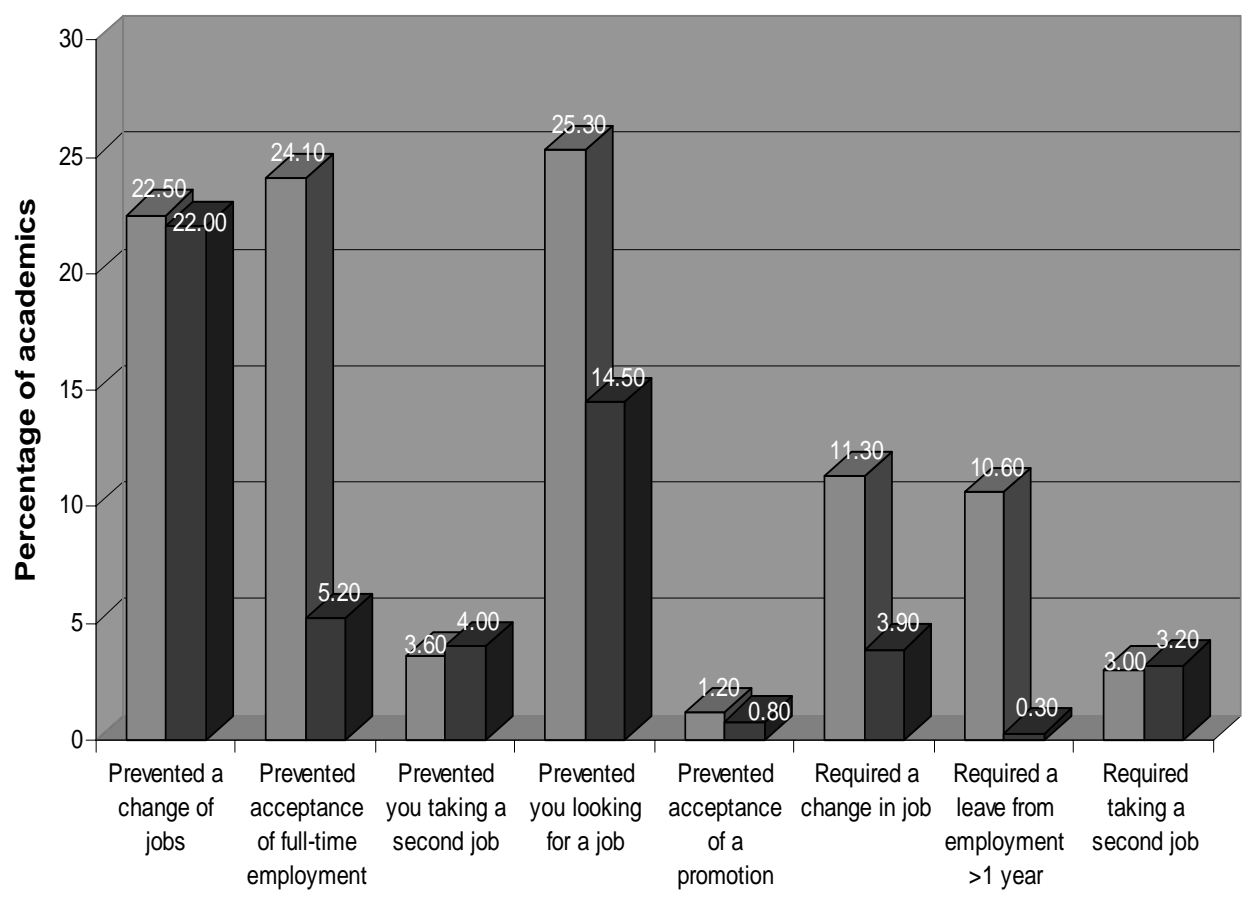


Figure 8 Average number of promotions received

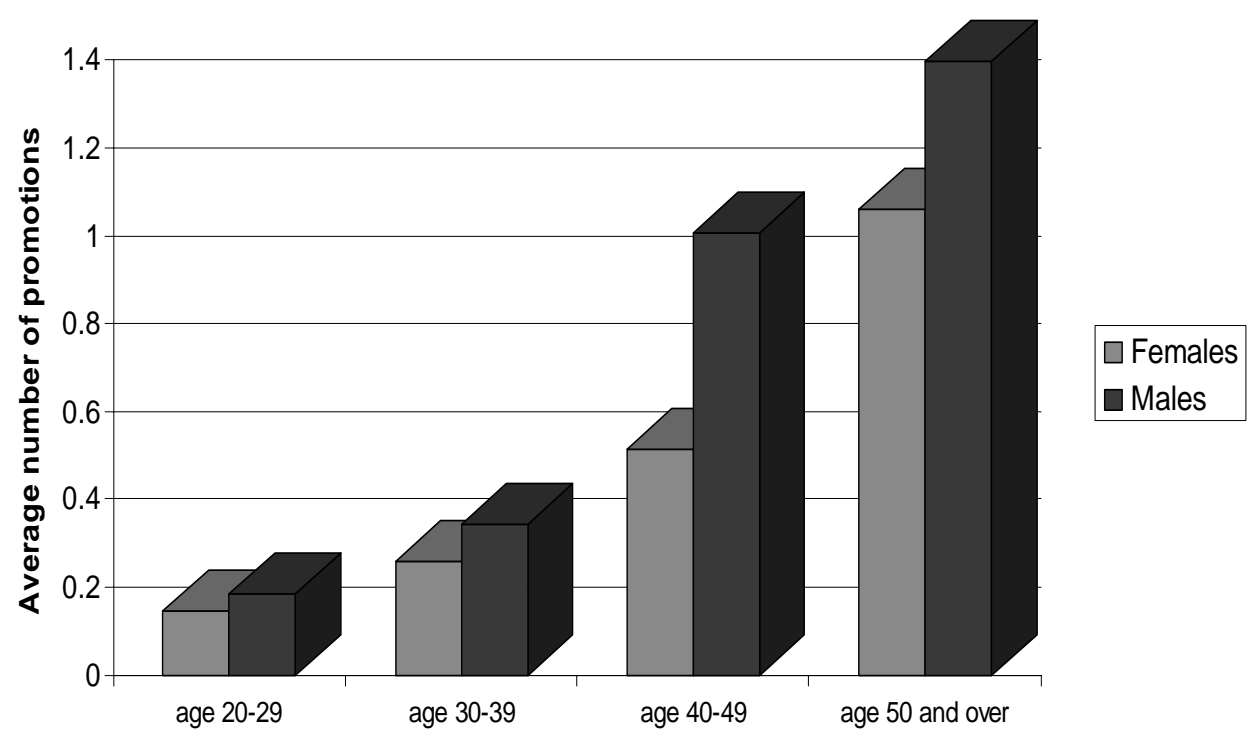

Figure 9 What academics think about their present salary in comparison with what they think they deserve to be paid

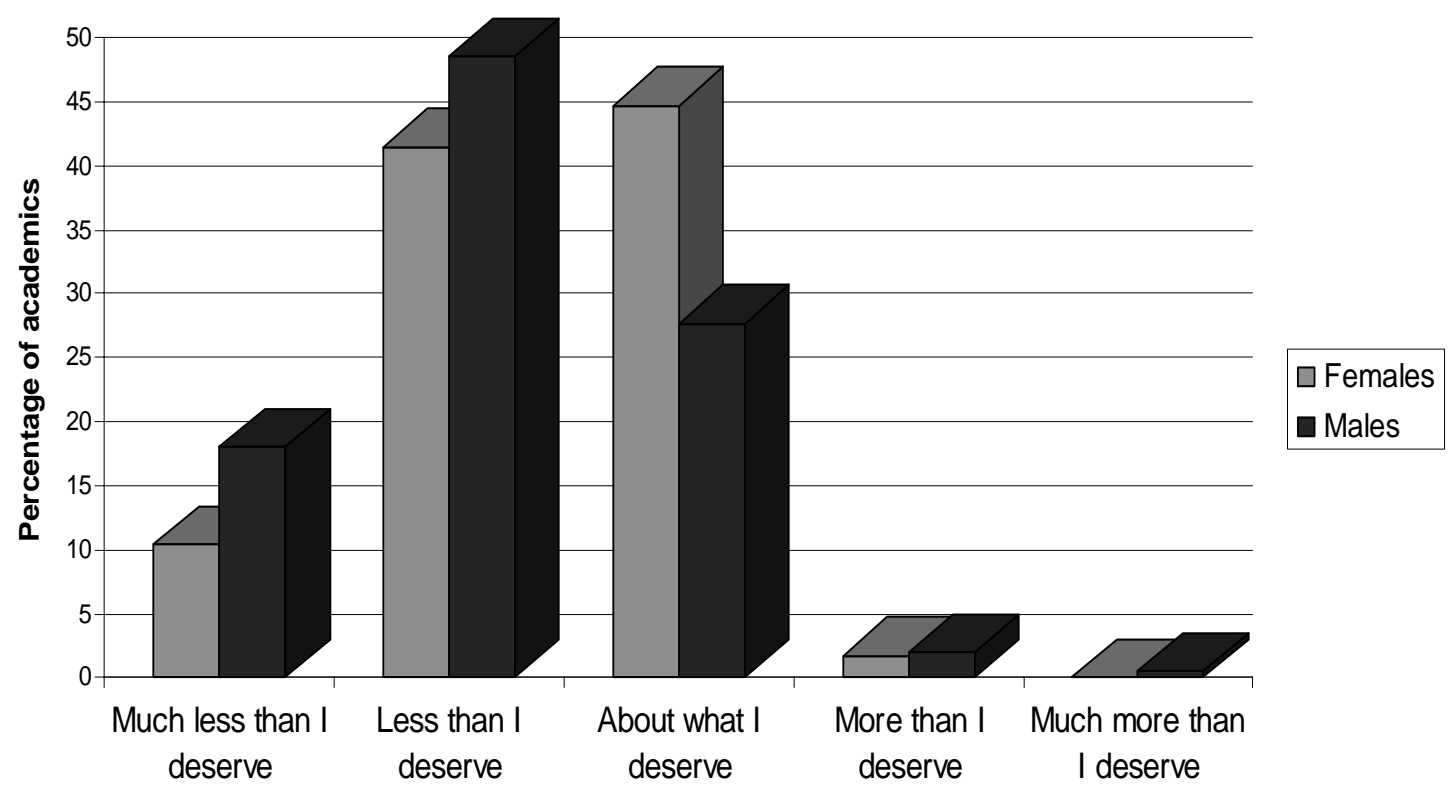


Figure 10 Advantages of an academic job

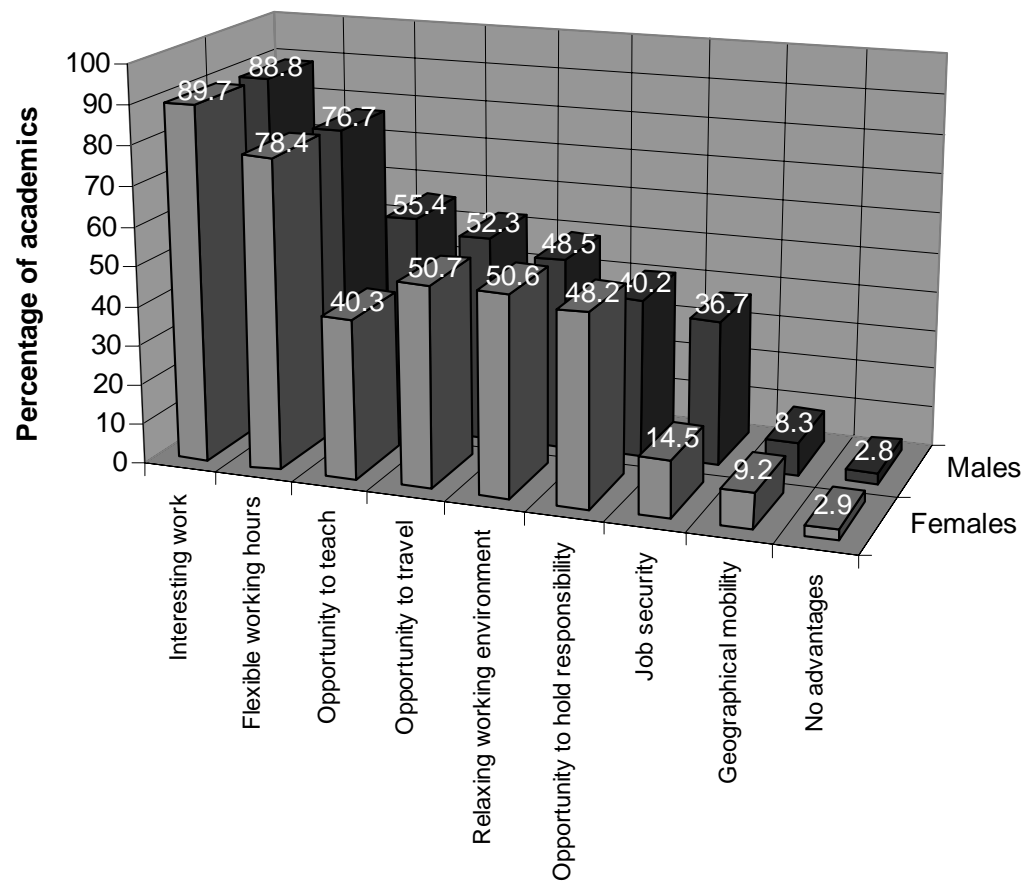

Figure 11 Disadvantages of an academic job

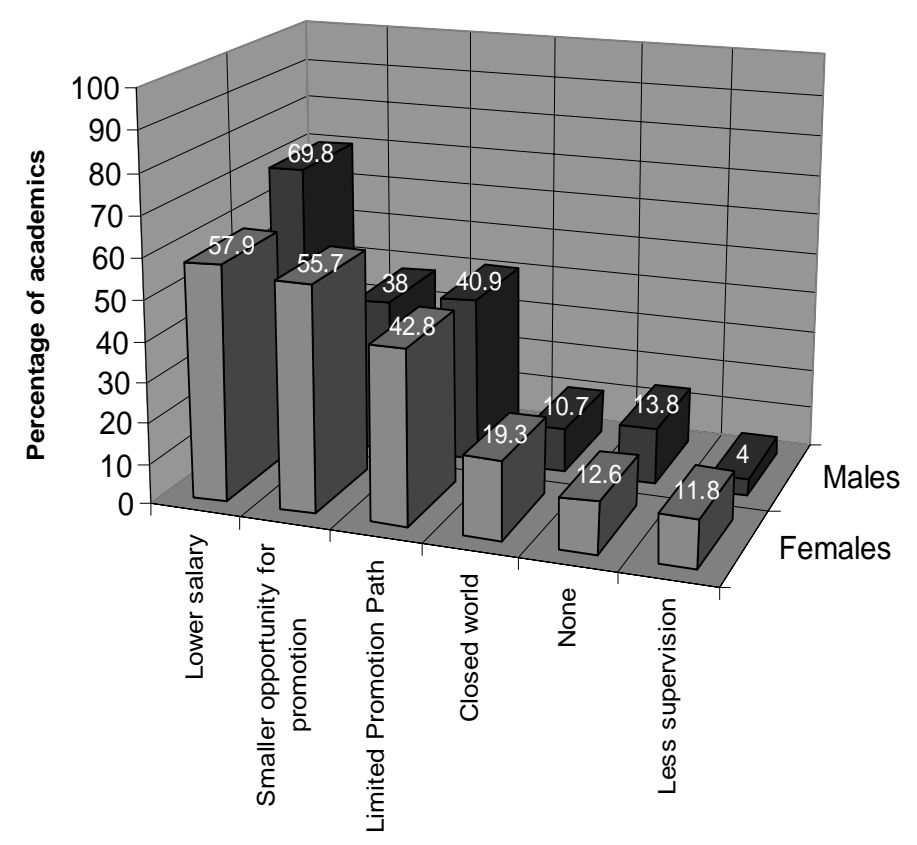


Figure 12 The average importance of factors - When looking for a job

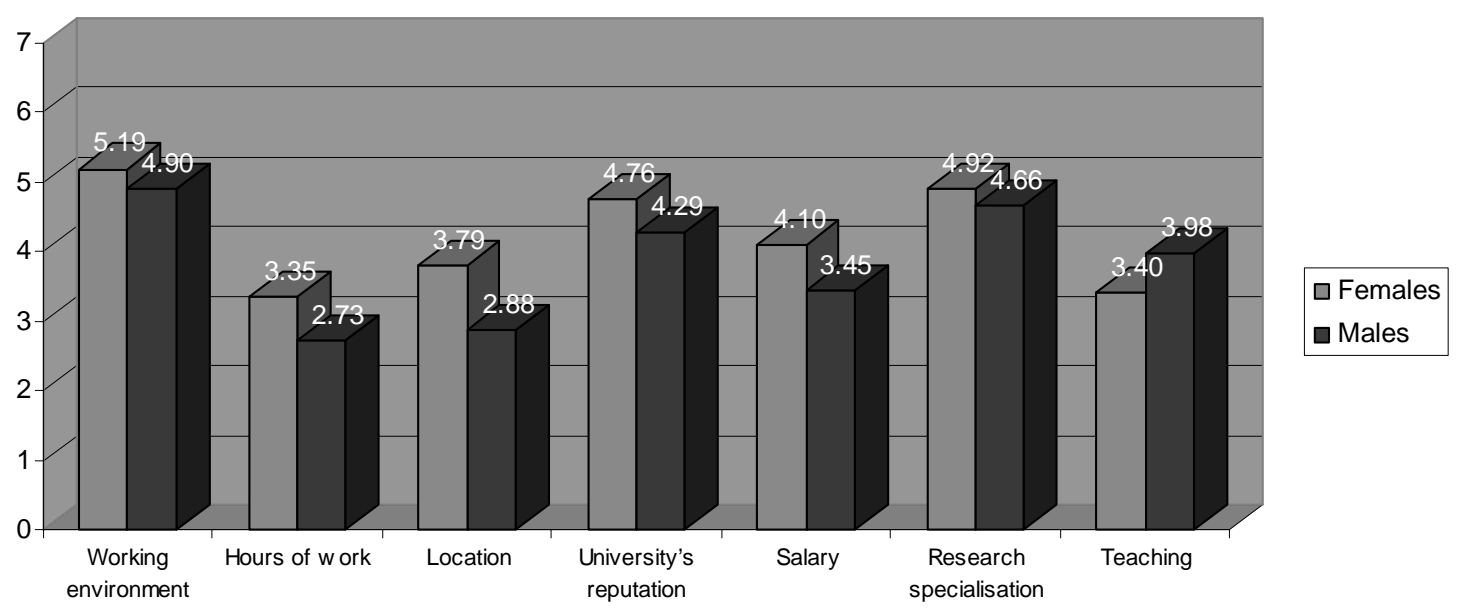

Figure 13 The average importance of factors - In their job at present

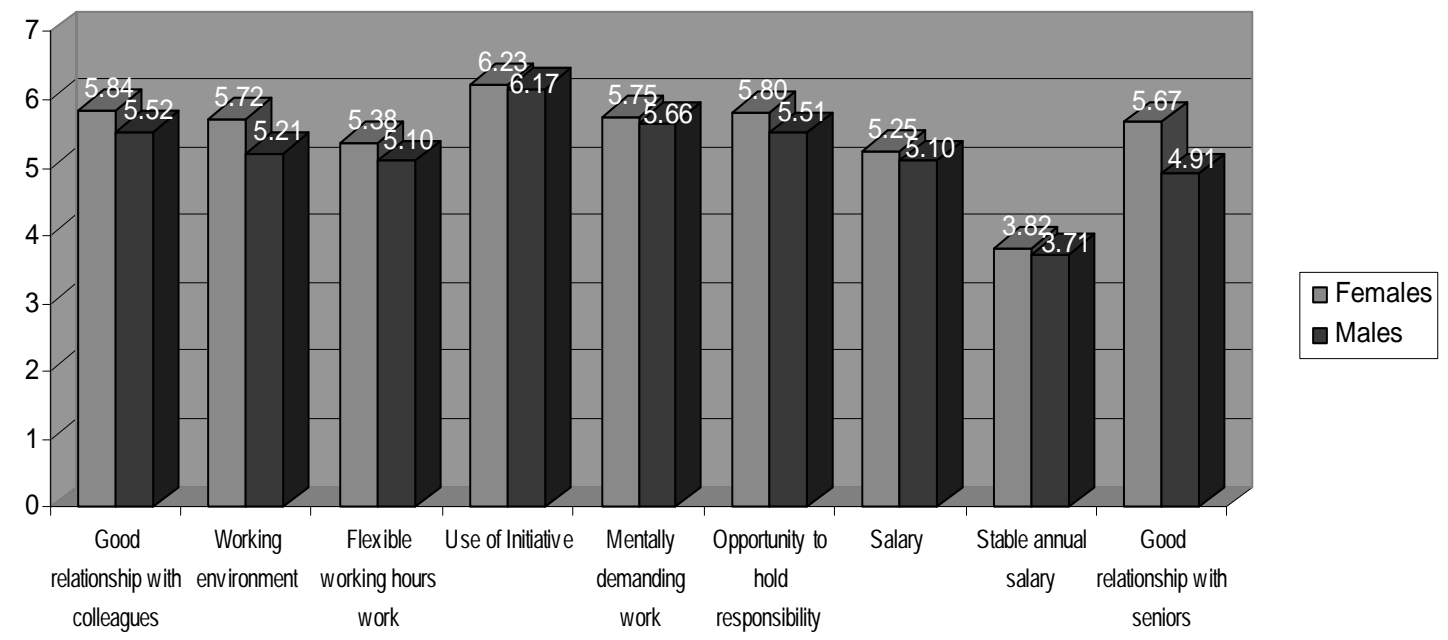

